Rev. Elev. Méd. vét. Pays trop., 1970, 23 (1) : 101-08

\title{
Contribution à l'étude de la culture dérobée de fourrages en rizière dans la région de Tananarive
}

\author{
par P. GRANIER et R. RAZAFINDRATSITA
}

\begin{abstract}
RESUME
La durée de la saison sèche et froide sur les Hauts Plateaux malgaches ne permet pas au bétail de maintenir une production et il est indispensable pour couvrir ses besoins d'avoir recours à une culture dérobée derrière le riz, qui occupe les seules terres riches.

Des essais portant sur la culture de l'ayoine, de la vesce et du chou fourrager ont permis de préciser les quantités d'eau nécessaires, les dates de semis, les rendements quantitatifs et qualitatifs pour chaque mode d'exploitation.

L'expérimentation montre que les cultures pures sont préférables aux cultures associées et que partout où l'on peut effectuer des semis précoces avec des possibilités suffisantes d'irrigation, l'avoine est supérieure à la vesce.

Le chou, malgré des rendements en matière sèche et azotée très intéressants est déconseillé car sa digestibilité n'est pas toujours parfaite et sa culture demande une façon culturale (repiquage) supplémentaire.

La culture dérobée de l'ayoine ou de la vesce, sujvant le cas, favoriserait l'intégration de l'élevage à l'agriculture, tout en influençant favorablement la production ultérieure de riz dans les parcelles ainsi traitées.

En précisant que ce fourrage vert n'est disponible qu'en fin de saison sèche.
\end{abstract}

\section{INTRODUCTION}

L'alternance des saisons a pour conséquence essentielle l'arrêt de la productivité du pâturage naturel à partir du mois de juin. Sans l'adoption de techniques appropriées le bétail pert durant la saison sèche le poids qu'il a gagné en saison des pluies, et une véritable production zootechnique est incompatible avec l'état de malnutrition, voire de dénutrition dans lequel se trouve le bétail en fin de saison sèche.

Si l'on veut maintenir le cheptel bovin en état au cours de la saison sèche et si l'on veut qu'il soit physiologiquement apte à produire (veaux, lait, viande), il faut couvrir ses besoins :
- énergétiques, donc lui donner du fourrage en quantité suffisante;

- en matières azotées, certains acides aminés étant indispensables;

- en carotènes, source de vitamine $A$, la plus importante pour le maintien de la productivité (fécondité).

Il faut remarquer qu'il existe une supplémentation traditionnelle à base essentiellement de paille de riz et de manioc. Mais si le bétail recevant une quantité suffisante de ces aliments peut conserver son poids, il ne peut pas maintenir une production, car ni les matières azotées, ni les carotènes n'existent dans la paille ou le manioc. 
Dans la zone où la culture du riz est la culture dominante, elle occupe la presque totalité des terres basses, humides, riches en matière organique et fertilisées, c'est-à-dire, qu'il n'existe pratiquement pas de terres riches en dehors de celles réservées à la riziculture.

Dans la mesure où faute de possibilités suffisantes d'irrigation ces rizières ne peuvent donner deux récoltes de riz dans l'année, et où l'on dispose cependant de la maitrise de l'eau, une culture dérobée de fourrages verts de saison sèche peut être valorisée par du bétail laitier ou d'embouche.

L'augmentation de la charge à l'hectare qui s'en suivrait permettrait secondairement d'accroître la production de fumier, ce qui faciliterait la mise en valeur des terres pauvres des plateaux et des pentes.

\section{LES ESPECES FOURRAGERES}

Depuis de nombreuses années des essais ont été effectués soit par les Instituts de recherches, soit par des particuliers. Ces essais concernent surtout deux espèces fourragères adaptées à l'hiver austral et cultivées sur les HautsPlateaux :

- l'avoine (Avena sativa, avoine de printemps);

- la vesce (Vicia sativa, vesce de printemps);

- le chou forrager (Brassica).

Ces fourrages sont utilisés seuls ou en association.

La présente note a pour objet de donner quelques précisions sur la production d'unités fourragères de ces espèces ainsi que sur leur valeur bromatologique afin de définir, s'il y a lieu, la vocation de l'une ou de l'autre en tenant compte et de leurs exigences en eau et de l'évolution des constituants du sol.

Dans la zone sédimentaire, des cultures dérobées sont pratiquées traditionnellement. Nous ne mentionnerons, à titre d'information, que la culture du pois du Cap (Phaseolus lunatus) pratiquée derrière la récolte du riz. On sème les graines, mélangées à une poignée de sable, au fond de trous de $20 \mathrm{~cm}$ de profondeur de façon à les mettre directement au niveau de la zone humide. Les chaumes du riz sont utilisés comme mulch. Après la récolte, les lianes sont distribuées au bétail.
Ces expérimentations effectuées ne concernent que la culture de l'avoine, de la vesce et du chou, dans la région de Tananarive.

Une espèce peut être utilisée également à contre-saison, c'est le soja (Glycine soja), mais la haute valeur nutritive de ses grains en fait en premier lieu un aliment de l'homme.

\section{EXPERIMENTATION 1967-1968}

\section{Protocole expérimentaI}

Au cours de la saison des pluies 1967-1968 une parcelle de 6 ares environ située dans un bas-fond a été cultivée en riz.

Cette parcelle ayant reçu une forte fumure minérale et organique au cours des années précédentes n'a pas été fertilisée avant la mise en culture (voir analyse du sol). Le riz, repiqué le 15 novembre 1967 a été récolté à la fin du mois d'avril et les semis précoces à contresaison, faits le 21 mai. Le sol a été labouré à la main et les semis faits à la volée.

Les choux (de $15 \mathrm{~cm}$ de hauteur) ont été repiqués à $50 \times 60 \mathrm{~cm}$.

Les semis ont été scindés en deux:

- semis précoces, le 21 mai;

- semis tardifs, le 20 juin.

Les coupes ont eu lieu au moment de la préfloraison.

\section{Observations}

\section{a) Irrigation}

Les parcelles ont été irriguées en aspersion. Le tuyau d'arrosage était muni d'un compteur volumétrique et les quantités d'eau ont été relevées pour chaque parcelle et totalisées.

Les résultats sont exprimés en $\mathrm{m}^{3} /$ hectare et comprennent :

- l'eau d'irrigation;

- les pluies enregistrées au pluviomètre pendant cette période.

Pluies de mai à octobre:

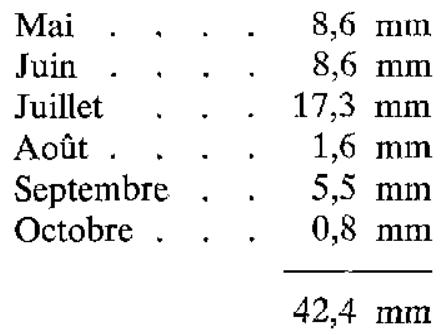




\section{Quantité d'eav $/ \mathbf{m}^{3}$}

\begin{tabular}{|c|c|c|c|}
\hline & $\begin{array}{c}\text { Irrigation } \\
\mathrm{m}^{4} / \mathrm{Ha}\end{array}$ & $\begin{array}{l}\text { Pluie } \\
\mathrm{m}^{3} / \mathrm{Ha}\end{array}$ & $\begin{array}{l}\text { TOTAL } \\
\mathrm{m}^{: / /} / \mathrm{Ha}\end{array}$ \\
\hline Avoine précoce & 4.259 & 420 & 4.679 \\
\hline Avoine tardive & 3.314 & 338 & 3.652 \\
\hline Vesce précoce & 2.890 & 357 & 3.247 \\
\hline Vesce tardive & 2.556 & 328 & 2.884 \\
\hline $\begin{array}{l}\text { Vesce } \times \text { avoine } \\
\text { précoce }\end{array}$ & 3.947 & 420 & 4.367 \\
\hline Vesce $\times$ avoine & & & \\
\hline tardive & 2.670 & 329 & 2.999 \\
\hline Chou & 3.825 & 335 & 4.160 \\
\hline
\end{tabular}

\section{b) Analyse du sol}

Un échantillon moyen du sol a été analysé avant la culture du riz. Deux échantillons moyens ont été prélevés après la récolte des fourrages respectivement dans les parcelles d'avoine (semis précoce) et de vesce (semis précoce). Ces échantillons ont été analysés par l'IRAM (voir plus loin).

\section{c) Cycle végétatif}

\begin{tabular}{|c|c|c|c|}
\hline \multicolumn{4}{|c|}{ Avoine (semis précoce) } \\
\hline Semis . . . . & . & . & 21 mai \\
\hline Levée . . . . & & & $26 \mathrm{mai}$ \\
\hline Hauteur $60 \mathrm{~cm}\left(1^{\mathrm{r}}\right.$ & & upe) & 18 juillet \\
\hline \multicolumn{4}{|l|}{ Avoine (semis tardif) } \\
\hline Semis . . . & . & . & 20 juin \\
\hline Levée . . . . & . & . & 28 juin \\
\hline Hauteur $90 \mathrm{~cm}$. & . & . & 11 septembre \\
\hline \multicolumn{4}{|l|}{ Vesce (semis précoce) } \\
\hline Semis . . . & . & . & $21 \mathrm{mai}$ \\
\hline Levée. & . & . & 29 mai \\
\hline Début de flor. (ht & 50 & $\mathrm{~cm})$ & 26 août \\
\hline \multicolumn{4}{|l|}{ Vesce (semis tardif) } \\
\hline Semis . . . & . & - & 20 juin \\
\hline Levée. & . & . & 29 juin \\
\hline Début de flor. (ht & 40 & $\mathrm{~cm})$ & 16 septembre \\
\hline \multicolumn{4}{|l|}{$\begin{array}{l}\text { Vesce } \times \text { Avoine } \\
\text { (semis précoce) }\end{array}$} \\
\hline Semis . . & . & . & 21 mai \\
\hline Levée avoine & . & . . & 26 mai \\
\hline Levée vesce. & . & . & 29 mai \\
\hline Floraison avoine & . & . & 12 août \\
\hline Floraison vesce. & . & . & 19 août \\
\hline \multicolumn{4}{|l|}{$\begin{array}{l}\text { Vesce } \times \text { Avoine } \\
\text { (semis tardif) }\end{array}$} \\
\hline Semis . . . & • & $\cdot$ & 20 juin \\
\hline Levée avoine & • & . & 28 juin \\
\hline Levée vesce . . & . & . & 29 juin \\
\hline Floraison avoine & . & . . & 16 septembre \\
\hline Floraison vesce . & . & . . & 2 octobre \\
\hline
\end{tabular}

Le 11 septembre, la deuxième coupe de l'avoine (semis précoce) coïncidait avec la première coupe de l'avoine (semis tardif).

Un semis très précoce effectuć le 7 mai n’a donné aucun résultat. Les semences ont été pratiquement détruites par les rats qui recherchaient les grains de paddy restés au sol.

\section{Résultats}

(Les résultats sont récapitulés dans le tableau $\left.\mathrm{n}^{0} 1.\right)$

a) Quantitatifs (matière sèche)

A chaque récolte, un échantillon moyen a été prélevé, pesé en vert et adressé immédiatement au Laboratoire de Chimie qui a dosé le pourcentage de matière sèche et effectué une analyse globale.

En ce qui concerne la production de matière sèche, l'avoine et le chou sont les plus intéressants, d'autant que la récolte, tant pour le chou que pour l'avoine est étalée sur plusieurs coupes (le chou est exploité par enlèvement des feuilles basales), ce qui facilite l'exploitation.

\section{b) Production d'unités fourragères}

L'analyse des échantillons a établi les valeurs fourragères suivantes, en se basant sur les coefficients de digestibilité étudiés en France.

\begin{tabular}{|c|c|c|}
\hline & & UF/ $/ \mathrm{kg} / \mathrm{sec}$. \\
\hline Chou fourrager & $\cdot \cdot$ & $\begin{array}{l}0,80 \\
\text { de } 067 \text { à } 071\end{array}$ \\
\hline Avoine précoce & - & de 0,67 à 0,71 \\
\hline Avoine tardive & . & de 0,69 à 0,71 \\
\hline Vesce précoce & & 0,51 \\
\hline Vesce tardive. & . & 0,57 \\
\hline Vesce $X$ avoine & précoce & de 0,61 à 0,66 \\
\hline Vesce $\times$ avoine & tardive & 0,65 \\
\hline
\end{tabular}

L'avoine et le chou sont nettement supérieurs à la vesce, leur production de matière sèche étant élevée ainsi que leurs valeurs fourragères, la vesce étant pénalisée par les coefficients de digestibilité de ses constituants.

\section{c) Production de matières azotées}

La production de matières azotées est donnée en «matières azotées totales". Mais du fait d'une similitude dans les coefficients de digestibilité de la matière azotée, les productions en «matières azotées digestibles» pourraient être classées de la même manière. 
TABLEAU $\mathbb{N}^{\circ} \mathrm{I}$

Tableau récapitulatif.

\begin{tabular}{|c|c|c|c|c|c|c|c|}
\hline & $\begin{array}{l}\text { Tonnes en } \\
\text { vert } / \mathrm{He}\end{array}$ & $\begin{array}{l}\text { Tonnes de } \\
\text { matière } \\
\text { sèche/Ha }\end{array}$ & $\left\{\begin{array}{c}\text { Unités } \\
\text { Fourrageres } \\
/ \mathrm{Ha}\end{array}\right.$ & $\begin{array}{l}\text { Matières } \\
\text { azotées } \\
\mathrm{Kg} / \mathrm{Ha}\end{array}$ & $\begin{array}{c}\text { Carotènes } \\
\mathrm{B} / \mathrm{Ha}\end{array}$ & $\begin{array}{l}\text { Calcium } \\
\mathrm{Kg} / \mathrm{Ha}\end{array}$ & $\begin{array}{c}\text { Irrigation } \\
\text { en } \mathrm{m}^{3} / \mathrm{Fa}\end{array}$ \\
\hline $\begin{array}{l}\text { Avoine précoce } \\
\text { lè coupe } \\
\text { 2è coupe } \\
\text { 3è coupe } \\
\text { Total }\end{array}$ & $\begin{array}{r}22,22 \\
29,22 \\
0,68 \\
52,12\end{array}$ & $\begin{array}{l}2,46 \\
4,80 \\
0,16 \\
7,42\end{array}$ & 5190 & $\begin{array}{l}477,2 \\
600 \\
22 \\
1099,2\end{array}$ & $\begin{array}{r}534 \\
2212 \\
19 \\
2765\end{array}$ & 25 & 4679 \\
\hline $\begin{array}{l}\text { Avoine terdive } \\
\text { lè coupe } \\
\text { 2è coupe }\end{array}$ & $\begin{array}{l}36,3 \\
0,76 \\
37,06\end{array}$ & $\begin{array}{l}6,46 \\
\frac{0,02}{6,48}\end{array}$ & 4530 & $\begin{array}{r}626,6 \\
2,6 \\
629,2\end{array}$ & $\begin{array}{r}800 \\
\frac{4}{804}\end{array}$ & 2 & 3652 \\
\hline Vesce précoce & 21,87 & 2,86 & 1450 & 832,2 & 1144 & 24,6 & 3247 \\
\hline Vesce tardive & 26,8 & 4,15 & 2360 & 1182,7 & 1124 & 31,1 & 2884 \\
\hline $\begin{array}{l}\text { Vesce } x \text { avolne précoce } \\
\text { lè coupe } \\
\text { 2è coupe }\end{array}$ & $\begin{array}{r}24,0 \\
0,3 \\
24,3\end{array}$ & $\begin{array}{l}3,93 \\
\frac{0,10}{4,03}\end{array}$ & 2530 & $\begin{array}{l}624,8 \\
\frac{11}{635,8}\end{array}$ & $\begin{array}{l}3199 \\
18,5 \\
3217,5\end{array}$ & 14,7 & 4367 \\
\hline $\begin{array}{l}\text { Vesce } x \text { avoine } \\
\text { terdive }\end{array}$ & 10,0 & 2,22 & 1440 & 275 & 341,8 & 8,6 & 3000 \\
\hline Chou fourreger & 42,2 & 7,0 & 5600 & 1316 & 680 & 128 & 4160 \\
\hline
\end{tabular}

La richesse en matières azotées de la vesce ( 28 p. 100 sur sec) permet à cette légumineuse de produire légèrement plus de matières azotées que l'avoine malgré une production de matière sèche nettement inférieure.

Il faut noter que dans tous les cas le rapport matières azotées/U.F. est très favorable et que la ration est toujours excédentaire en matières azotées - sauf avec la vesce $X$ avoine tardive.

\section{d) Production de carotènes}

L'association vesce $X$ avoine précoce ainsi que l'avoine précoce sont nettement supérieures aux autres fourrages et comme pour les matières azotées tous ces fourrages sont largement excédentaires.

\section{e) Production de calcium}

Les légumineuses ont toujours des teneurs en $\mathrm{Ca}$ plus élevées que les graminées. Ce fait est confirmé par les analyses qui donnent les compositions suivantes:
TABLEAU $\mathbb{N}^{\circ}$ II

Teneurs en carotènes en $\mathrm{mg} / \mathrm{kg}$

\begin{tabular}{|c|c|c|c|}
\hline \multirow[b]{2}{*}{ Avoine } & $\begin{array}{c}\text { Hurnilité } \\
\text { Pour centage }\end{array}$ & Brut & Sec \\
\hline & & & \\
\hline Frécoce & $\begin{array}{l}88,9 \\
83,6 \\
76,1\end{array}$ & $\begin{array}{l}24 \\
75 \\
62\end{array}$ & $\begin{array}{l}217 \\
461 \\
260\end{array}$ \\
\hline Tardive & $\begin{array}{l}82,2 \\
71\end{array}$ & $\begin{array}{l}22 \\
61\end{array}$ & $\begin{array}{l}124 \\
21.1\end{array}$ \\
\hline Vesce & & & \\
\hline Précoce & 86,9 & 52 & 400 \\
\hline Terdive & 84,5 & 42 & 271 \\
\hline Vesce $x$ aroine & & & \\
\hline Précoce & $\begin{array}{l}83 \\
67,1\end{array}$ & $\begin{array}{r}133 \\
61\end{array}$ & $\begin{array}{l}814 \\
185\end{array}$ \\
\hline Taraive & $\begin{array}{l}84,5 \\
77,8\end{array}$ & $\begin{array}{l}42 \\
34\end{array}$ & $\begin{array}{l}271 \\
154\end{array}$ \\
\hline Chou fourrager & 86,8 & 13 & 97 \\
\hline
\end{tabular}


Chou . . . . $18,4 \mathrm{~g} / \mathrm{kg}$ de mat. sèche

Vesce précoce . $8,6 \mathrm{~g}$

Vesce tardive . . 7,5 $\mathrm{g}$

Vesce $\times$ avoine. de 3,4 à $3,9 \mathrm{~g}$

Avoine précoce . de 3,3 à $3,6 \mathrm{~g}$

Avoine tardive . de 2,8 à $3,1 \mathrm{~g}$

Les besoins en calcium d'un bovin adulte se situent entre 12 et $15 \mathrm{~g}$ de calcium par jour $(0,3$ p. 100 de la ration totale) mais peuvent aller jusqu'à 0,8 de la ration pour un jeune en croissance. Il s'en suit que si nous considérons le fourrage le moins riche, telle l'avoine, nous voyons que même dans ce cas, les besoins d'un adulte sont couverts puisque l'ingestion de matière sèche qui est de l'ordre de $2,2 \mathrm{~kg}$ par $100 \mathrm{~kg}$ de poids vif apportera, pour un animal de $300 \mathrm{~kg}$ :

\section{$3 \times 2,2 \times 2,8=18,48 \mathrm{~g}$ de calcium}

Il n'en va pas de même pour un jeune en croissance dont les besoins plus élevés ne pourront être couverts que par les légumineuses (vesce) ou le chou.

On retrouve ici cette insuffisance en calcium que l'on remarque dans tous les aliments du bétail cultivés sur les Hauts-Plateaux de Madagascar, et qui nécessite une supplémentation de la ration en calcium quel que soit l'aliment de base. (Supplémentation avec de la poudre d'os, de la chaux ou des coquilles pilées).

\section{f) Besoins en eau}

Les quantités d'eau reçues dépendent de la physiologie propre à chaque espèce mais également et surtout des quantités de matière sèche produites et de la durée de l'exploitation, si bien que l'avoine et le chou ont exigé plus d'eau que la vesce et la vesce $X$ avoine tardive.

Ces fourrages sont relativement exigeants en eau, puisque les quantités d'eau nécessaires pour $1 \mathrm{~kg}$ de matière sèche sont de l'ordre de 600 à 630 litres pour le chou et l'avoine, alors que pour une espèce adaptée à la sécheresse comme le sorgho 2751 . suffisent.

Ces volumes d'eau utilisés (de l'ordre de $4.000 \mathrm{~m}^{3} / \mathrm{ha}$ ) sont compatibles avec une exploitation de type paysannal. Les surfaces à cultiver ne dépasseraient pas un hectare, et un canal ayant un débit de $21 . / \mathrm{sec}$. seulement permet de disposer de $172 \mathrm{~m}^{3}$ /jour, et de limiter le nombre de jours d'irrigation à 23 pour une période de culture de 160 jours environ.

\section{g) Evolution des constituants du sol}

Nous donnons ci-après les bulletins des analyses effectuées par l'IRAM concernant des échantillons des sols prélevés :

$N^{\prime \prime} 1$ : avant la double culture

$\mathrm{N}^{0} 2$ : après l'avoine

N* 3 : après la vesce

La légumineuse enrichit le sol en azote, en matière organique et élève le taux d'acide phosphorique assimilable. Elle exporte essentiellement de la potasse.

La graminée a exporté en quantités nettement plus élevées de l'azote, de l'acide phosphorique, de la potasse et du sodium.

La culture dérobée de légumineuses est sur le plan de la fertilité des sols plus économique que la culture de graminées plus épuisantes.

La vesce doit être suivie d'un apport de potasse, et l'avoine implique l'emploi d'un engrais complet.

\section{h) Charge à l'hectare}

On admet que les besoins en unités fourragères pour une tête de bétail amélioré, telle que celles que l'on peut rencontrer sur les Hauts-Plateaux, sont de l'ordre de $6 \mathrm{UF} /$ jour pour un bœuf à l'embouche ou une vache laitière produisant 6 litres par jour. La charge que peut supporter un hectare d'avoine ou de vesce produisant environ 3.000 UF (en milieu paysan) disponibles à partir du 15 juillet est la suivante.

- Besoins globaux pour une tête du 15 juillet au $1^{\text {er }}$ novembre:

$$
6 \times 110=660 \mathrm{UF}
$$

- Si l'on admet 10 p. 100 de pertes, les besoins deviennent :

$$
660+\frac{10}{100}=726 \mathrm{UF}
$$

- Charge possible :

$$
\frac{3.000}{726}=4 \text { têtes environ }
$$


TABLEAU $\mathbb{N}^{\circ}$ III

Anelyse du sol

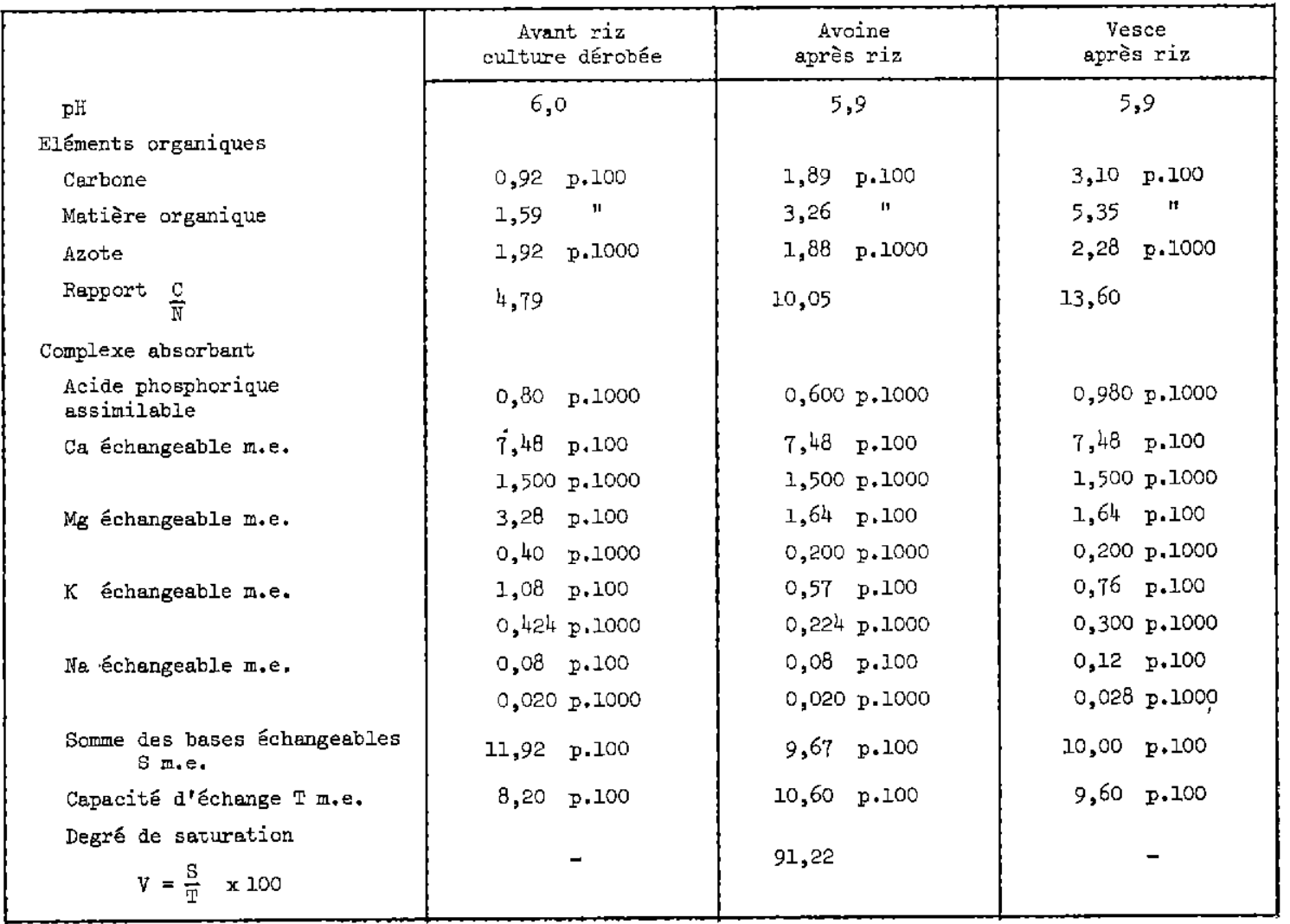

D'après I'IRAM.

TABLEAU N $\mathrm{N}^{\circ}$ IV

Anglyses fourragères

Résultats pour $100 \mathrm{~g}$. de produit sec (cr g.)

\begin{tabular}{|c|c|c|c|c|c|}
\hline Détermination & $\begin{array}{l}\text { Avoine } \\
\text { précoce }\end{array}$ & $\begin{array}{l}\text { Vesce } \\
\text { précoce }\end{array}$ & $\begin{array}{l}\text { Vesce } \\
\text { tardive }\end{array}$ & $\begin{array}{l}\text { Astiocint lon } \\
\text { Vessed/Avoine }\end{array}$ & Chou \\
\hline Composition & & & & & \\
\hline Eau & - & - & - & - & - \\
\hline Matières minérales & 11,76 & $1 !, 28$ & 10,80 & $1], 8\}$ & 11,52 \\
\hline Matières grasses & 3,83 & 4,$6 ;$ & 5,80 & 4,12 & 4,56 \\
\hline Matières azotées & 12,50 & 29,19 & 28,54 & 15,98 & 78,86 \\
\hline Cellulose brute & 25,63 & 18,16 & 19,33 & 19,61 & 8,05 \\
\hline $\begin{array}{l}\text { Extractif non azoté } \\
\text { (Glucides, composés pectiques } \\
\text { etc.) }\end{array}$ & 46,28 & 33,72 & 35,53 & $1,8,41$ & 54,01 \\
\hline Détermination complémentaires & & & & & \\
\hline Insoluble chloridrique & 2,11 & 0,44 & 0,21 & 1,71 & 0,39 \\
\hline Phosphore (en P) & 0,397 & 0,631 & 0,539 & 0,341 & 0,316 \\
\hline Calcium (en $\mathrm{Ca}$ ) & 0,365 & 0,869 & 0,753 & 0,740 & 1,840 \\
\hline
\end{tabular}




\section{DISCUSSION}

Si l'on compare les différentes productions analysées dans la présente note et récapitulées dans le tableau $n^{\circ}$ IV on peut tirer les conclusions suivantes:

a) Dans une exploitation où l'on peut disposer de moyens suffisants d'irrigation et employer une fertilisation d'entretien, il y a intérêt à cultiver de l'avoine seule à contre-saison.

b) Si l'on cultive de l'avoine, il faut faire des semis précoces sinon on peut perdre une coupe.

c) Si l'on n'est pas sûr d'avoir la maîtrise de l'eau et en particulier si les sols demeurent engorgés après la récolte du riz et si les sols sont pauvres, on peut avoir intérêt à utiliser la vesce.

d) Si l'on cultive de la vesce, les semis doivent être faits tardivement (en juin).

Ceci peut présenter un intérêt dans le cas d'une rizière récoltée en retard. Une culture d'avoine ne donnera qu'une coupe, et ne sera donc pas compétitive avec une seule coupe de vesce.

e) Il semble que dans aucun cas on n'ait intérêt à cultiver une association vesce-avoine, ces deux espèces dans l'écologie des HautsPlateaux et d'après ce qui précède (cycles végétatifs différents) ne se comportent pas comme une véritable association, ma1s sont en réalité en compétition, en particulier pour la lumière.

f) Un parasitisme intense a été observé sur le chou fourrager, et a nécessité un traitement au Naphtyl (Sevin) contre une chenille, larve de Plutella maculipennis ou teigne des crucifères et un puceron, Brevicoryne Lorassicae.

Cet inconvénient ajouté au fait que le chou peut avoir une mauvaise digestibilité dans certains cas et que le repiquage nécessite une façon culturale supplémentaire, font qu il faut être prudent avant de préconiser la culture du chou en vulgarisation, malgré des rendements en matière sèche et matières azotées très intéressants. g) La culture dérobée favorise le rendement ultérieur de la rizière car :

- son assèchement avant la récolte perinet de lutter contre les nématodes;

- l'aération du sol favorise l'activité microbienne;

- une deuxième culture diminue l'importance des adventices et réduit les sarclages;

- la fumure organique de la culture dérobée améliore la riziculture qui peut supporter les frais d'une fertilisation en début de campagne;

- un revenu monétaire supplémentaire s'ajoute à la production rizicole, ce qui permet l'amélioration de la culture principale (investissement en matériel essentiellement).

\section{CONCLUSION}

La culture dérobée, en rizières, à contresaison de fourrage peut apporter non seulement l'énergie mais les éléments indispensables à l'équilibre de l'alimentation du bétail en saison sèche (matières azotées, carotènes).

Elle permettrait d'exploiter les potentialités maximales des seules terres riches dont dispose actuellement le paysan des Hauts-Plateaux malgaches, et en augmentant la charge à l'hectare faciliterait le démarrage de la mise en valeur des terres hautes (production en fumier).

L'exploitation de fourrages riches en fin de saison sèche permettrait de maintenir la production lactée et d'éviter la dénutrition des vaches laitières.

Dans le cadre de l'embouche, on sait qu'actuellement, les éleveurs ne peuvent engraisser des boufs qu'entre les mois de janvier et de juillet à cause du manque de fourrage de contre-saison. La pratique de la culture dérobée permettrait d'emboucher un deuxième bouf et de pouvoir vendre un animal «fini » à la boucherie à un moment de l'année où l'approvisionnement fait défaut aussi bien en quantité qu'en qualité, et où les prix élevés valoriseraient le travail de l'éleveur. 


\section{SUMMARY}

\section{Contribution to the study of the catch crop of fodder in rice-fields}

in the Tananarive region

In the High plateau of Madagascar, the cattle may not keep a production during the cold and dry season, so a catch crop after the rice, that covers the only rich lands, is absolutely necessary for its needs.

The necessary quantities of water, the tume of seedings, the quantitative and qualitative yields for every sort of exploitation could have been specified by trials of cultures of oats, vetch and kale.

The experimentation indicates that single cultures are better than the associated cultures and wherever the early seedings with adequate possibilities of irrigation are possible, the oats is better than vetch.

In spite of very interesting yields in dry and nitrogen matters, the cabbages is not recommended, its digestibility being not always correct and its cultivation requiring a supplementary cultural method (planting out).

The catch crop of oats or vetch would help the mixed-farming, and would influence favourably the further production of rice in the so cultivated plots.

\section{RESUMEN}

\section{Contribución al estudio del cultivo intermedio de forrajes en arrozal en la region de Tananarive}

La duración de la estación seca y fria en las Altas Mesetas malgachas no permite al ganado mantener una producción. Es indispensable para satisfacer sus necesidades acudir a un cultivo intermedio detrás del arroz, que ocupa las solas tierras ricas. Ensayos sobre el cultivo de la avena, de la veza $y$ de la col forrajera permitieron precisar las cantidades de agua necesarias, las fechas de siembra, los rendimientos cuantitativos y cualitativos para cada modo de explotación.

La experimentación muestra que se prefieren los cultivos de la misma especie a los cultivos asociados y que, en todas partes donde se pueden efectuar siembras tempranas con posibulidades suficientes para el riego, la avena es superior a la veza.

Se desaconseja la col, a pesar de los rendimientos de materia seca y nitrogenada muy interesantes, por que no es siempre perfecta su digestibilidad y su cultivo necesita un modo cultural suplementario (trasplante). El cultivo intermedio de la avena y de la veza, según el caso, favoreceria la integración de la cria con la agricultura, al influjr favorablemente la producción ulterior del arroz en las parcelas asi cultivadas. 